\title{
Analysing Pedestrian Safety in School Zones Based on Behaviour Risk
}

\author{
T.W.K.I.M. Dias and D.K. Wickramarachchi
}

\begin{abstract}
Generally, one of the most vulnerable road user categories that could be recognized is pedestrians, thus their susceptibility to high injury severities in road vehicle crashes. In Sri Lanka, the risk of pedestrian safety near school zones has increased rapidly with the growth of areas such as infrastructure development, socio-economic development, etc. This research was focused to address the pedestrian safety issues based on behaviour risk of school children near Colombo zone. The data collection for this study was conducted under three categories which include: a road inventory data collection, road crash data collection and a pedestrian road risk behaviour data collection. Moreover, two factors were given priority: the user behaviour at pedestrian crossings and user behaviour at sidewalks. The data collection on the pedestrian behaviour risk was done manually, focusing on school uniformed children. Past road crash data from the Sri Lankan Traffic Police database were also used to estimate normalized values. Behaviour risk value for each school zone was estimated in order to identify whether any safety improvements were required. Vulnerability for not using sidewalks was $15 \%$ on average and the vulnerability for not using pedestrian crossings was less than $10 \%$ for all school gates considered in both morning and afternoon times. Results indicated that the vulnerability risk is low compared to studies found in literature.
\end{abstract}

Keywords: Pedestrian safety, Pedestrian behaviour risk, Vulnerable road users, Crossing safety

\section{Introduction}

As a matter of fact, one of the most vulnerable road user categories that could be recognized is pedestrians. Unlike the passengers inside a vehicle, their bodies are directly exposed to an injury when it comes to motor vehicle crashes. Subsequently, they are susceptible to higher severities at a motor vehicle crash. Eventually motor vehicle crashes have become a substantial concern in the world with the increase of population, urbanization and due to road rule violations by both drivers and pedestrians.

According to Sri Lanka Traffic Police data from $2019,27 \%$ of the crashes involve pedestrians. When the fatalities are concerned, $18 \%$ of the fatalities are pedestrians, whereas that figure for the entire South Asia is 14\% [1]. When the Sri Lankan crash data related to children related crashes are considered within 2014 to $2017,45 \%$ of those crashes have happened with no pedestrian crossing within 100 meters, 10\% having a pedestrian crossing within 50 meter reach and $3 \%$ hitting outside sidewalks.

Further, when considering developing countries, India showed an alarming pedestrian injury proportion percentage of $41 \%-75 \%$, taken from traffic crash distributions from 2014 to 2018 [2].

Generally, pedestrian crashes are more likely to occur at pedestrian crossings on the roads where it has been studied that $63 \%$ of pedestrian crashes in the USA from years 1995 to 1998 and $79 \%$ of pedestrian crashes in the year 2004 in Australia have occurred while attempting to cross the roads [3]. Moreover, schools could be considered as a vital factor when considering pedestrian safety of children where number of studies have been conducted to investigate factors affecting pedestrian safety near school zones. It was identified that number of pedestrian collisions, travel times near the school and the neighbourhood characteristics around the school were some key features in those studies [4]. Pursuing this further, it can be said that pedestrian crashes are still a major issue that school children face with, since significant number of crashes near

Eng. (Dr.) (Ms.) T.W.K.I.M. Dias,

AMIE(SL), PhD (USA), MSc (Moratuwa), BSc EngHons (Moratuwa), CMILT(SL), Senior Lecturer, Department of Civil Engineering, General Sir John Kotelawala Defence

University, Kandawala Road, Ratmalana, Sri Lanka. Email:ishanidias@kdu.ac.lk

(D) https://orcid.org/0000-0003-2503-5720

Mr. D.K. Wickramarachchi,

Undergraduate, BSc. Eng, Department of Civil Engineering

General Sir John Kotelawala Defence University

Kandawala Road, Ratmalana, Sri Lanka. 
schools have occurred related to pedestrian crossings and sidewalks. School zones are focal points of children activities anywhere in the world. The time spent by a student on road and the neighbourhood characteristics of schools play a significant role when it comes to the safety of a school child [5].

The main schools in Colombo, Sri Lanka are located on busy roads with higher traffic flows, which do not support the said factors.

Therefore, this research was focused to address the pedestrian safety based on behaviour risk for school children in the Colombo area. Mainly two behaviour types were considered in the study: the user behaviour at pedestrian crossings and user behaviour at sidewalks.

\section{Literature Review}

\subsection{School Children and Road Safety}

Barton and Schwebel (2007) studied the relationship between age and unsupervised pedestrian behaviour using a 'pretend road' method [6]. Their results showed that, wait times, attention to traffic, missed opportunities, and gap sizes were positively related to age. They also found that girls waited longer than boys when the gender effect was tested. Their results showed that 5- and 6-year-old children tended to display the most dangerous behaviours on the road. Also, compared to 7and 8- year-olds, younger children have taken more risks that included more near-collision situations in their 'pretend road' set up [6].

\subsection{Behaviour Study on Pedestrians at Pedestrian Crossings}

Hamed (2001) conducted a study on analysis of pedestrian behaviour at pedestrian crossings, and studied pedestrian behaviour at crossroads, through the aid of several models presented, based on the fact whether a particular street is divided or undivided [7]. According to these models, pedestrian behaviour at crossroads differed based on the waiting time and the number of attempts. Hamed argued that the reasons for it to differ according to those two factors could be various parameters such as age, gender, city of living, the place intended to reach, number of people crossing the road at the particular moment, past bad experiences in crossroads etc. Further, it was mentioned that the number of attempts made may depend on the particular waiting time, regardless of whether the streets are divided or undivided. Moreover, it was understood that there was an increased risk when these crossings are near centred pavements on divided roads. The study also showed that the pedestrian behaviour on crossings could be contrasting when walking towards the refuge, stopping and at the beginning of a new cross in order to reach the destination.

According to the study conducted by Leden et al. (2006) for the year 2000, the government of Sweden had been quite strict on the driver errors caused at marked pedestrian crossings [8]. Referring to a major study, it was learnt that the risk of accidents on marked crossings which were un-reconstructed has increased for both cyclists and pedestrians. The argument was that the safety side would worsen if the driver speed issue remained unsolved and unattended. It was understood that solving of the speed issue alone would not solve everything. Moreover, the study explained how sites were good places to improve speed related matters. Several studies which included sites near schools have proved that they had more clarity, visibility and orientation and were much likely to have more safety as well. Further, it was suggested that marking of the crossings properly and marking the different expected speed levels would also be helpful when ensuring safety aspects.

\subsection{Pedestrian Safety near Schools}

The initial objective of Andreou's (2009) research was to investigate whether the road environment balanced with the needs of the younger pedestrians especially near the school zones [9]. Developing an interview schedule, using a qualitative approach with professionals, a case study was conducted with four selected schools in five sections under the topics on the first impression, street and traffic, footpaths, public transport and pedestrian facilities. It was identified that improving pedestrian and walkway facilities were essential and the following five key planning principles aimed to reduce car usage and to improve pedestrian safety around the schools. Five key planning principles were connected during the study which were street networks, clear lines of sight, footpaths, parking facilities and promoting variety of land use types with accessible transport. Further, it was also understood that the schools should not plan for safety within its bounded gates.

The objective of the study reported by Transportation Services Publication (2014) was 
to propose a strategy for improving safety around school zones [10]. The concept for this study was developed based on school zone related pedestrian collision data, detailed safety reviews which were conducted at high collision school clusters, and the current school road safety programs and engineering tools. An analysis was conducted on the pedestrian collisions that occurred around school areas over 10 years to identify trends and patterns. The data was filtered to include only events that involved pedestrians between four and nineteen years of age, occurred between Monday and Friday during the school term, and between the hours of 7:00 and 9:00 a.m. and 2:00 and 5:00 p.m., in order to identify school aged pedestrian collisions. These parameters typically represented a school that would be in session. A methodology developed by the Transportation Services was used for this study where it had defined a school zone within $1 \mathrm{~km}$ radius. This was based on the eligibility distance for school bus transportation adopted by both school boards in Toronto and the reasonable assumption that most students would be driven to school if they live beyond this distance [10]. Warsh et al. (2009) studied children related crash data in Toronto between 2000 and 2005 and found that, size of school zone along the roads has negatively affected the number of crashes and it ranges even up to $450 \mathrm{~m}$ radius [5].

A study done by Sharmeen \& Israt (2013) had its objectives to find a safer environment for children on their way to and from school [11]. It was seen that more children walked to school than cycling which decreased the traffic congestion during, before and after school. It was identified in five case studies around the selected schools. Further, an opinion survey was conducted regarding roadside access facilities. It was understood from the opinion survey that awareness should be raised among students, guardians and the security guards. Moreover, it was concluded that maintenance of smooth pavement surfaces and low slopes were to be taken account of. Pursuing this further, a design of proper parking spaces near schools and building of safe crossings of overhead bridges or underground tunnels were to be considered as well. It was also identified that there were severe accessibility and mobility problems around the schools that were complex and highly interrelated. Additionally, it could be mentioned that these problems demanded greater co-operation between all concerned, i.e., policymakers, transport planners, traffic engineers, school administrators, drivers, parents and students, and possibly others who may have knowledge or expertise regarding the safety and mobility issues around schools.

\subsection{Pedestrian Behaviour Risk Value}

A study was conducted by Kourtellis et al. (2013) to develop a 'risk score' (see Equation 1), to measure the behaviour of road users at selected sites in Hillsborough and Miami-Dade counties in Florida, USA [12].

User risk score $=\sum_{i} P_{i} \times W_{i}$

where, $i$ represents the different surrogates, $P$ is the proportion of the users and $W$ is the weight of each surrogate used in the study. Some of the weights considered were "user crossing on crosswalk" as 0, "user not crossing on crosswalk" as (-2), and "user crossing on user green signal" as 1 etc.

Surveys were conducted in June-July 2012 in two counties in Florida with the highest pedestrian crashes and fatalities to collect data in order to establish baseline conditions. These surveys included opinion surveys of pedestrians and observations of pedestrians and cyclists, along with their interaction with drivers. Moreover, the locations were selected based on site characteristics including pedestrian treatments or features, crash history and land use. Results showed that the majority of sites exhibited unsafe behaviour from pedestrians, cyclists and drivers. From the two observed locations, percentage of users who did not walk on sidewalk was about $4 \%$ on average, and the percentage of users not crossing on crosswalk was about $24 \%$ on average[12].

Perera et al. (2017) in their study on analyzing pedestrian safety in School Zones, analyzed the behavior of pedestrian behavior in selected school zones in Kandy city, Sri Lanka [13]. They considered all pedestrians regardless of their age, but they have not mentioned the percentage of school children they observed in the average pedestrian counts they recorded. The parameters they considered were, not using walking zones, running on the road, crossing road without pedestrian crossing, illegally parked vehicles, and overtaking on the pedestrian crossing. Some of these parameters can be identified as pedestrian behaviours, some were road infrastructure details, and one was a driver behaviour. However, they have not observed any overtaking at pedestrian 
crossings. They proposed the vulnerability equation considering, the number of vulnerable incidents related to criterion, average number of pedestrians/vehicles in the zone. However, considering the average number of pedestrians and vehicles in the zone, exposure values they mentioned do not seem correct. For example, risk takers who do not use a marked crosswalk should be considered versus the exposure value of only the total number of pedestrians who crossed the roads. Inclusion of those who did not cross the roads in the denominator of the vulnerability equation is inaccurate. Hence, in the current study, those issues were corrected, and modified definitions are proposed in the Methodology section, without taking those equations as they were.

Instead of calculating Equivalent Property Damage Only (EPDO) crashes, Perera et al. (2017) have converted all crashes into nongrievous crashes, which is not a very common procedure to do [13]. In this study, a full equation of EPDO was used from a working document with the consent of the authors, and their first publication of the full equation was in 2021 [14].

\section{Methodology}

This research was initially conducted using two approaches based on the vulnerability concept. Correspondingly, this concept for school children was analyzed considering two factors as mentioned below.

1. Pedestrian behavior at crossings

2. Pedestrian behavior at sidewalks

After the data collection procedure as mentioned below, this data was used to determine parameters such as Vulnerability values, Normalized Vulnerability values, Equal Property Damage Only (EPDO) values and consequently to analyze the pedestrian behavior risk values using the relevant equations.

\subsection{Selection of Schools}

In general, Colombo could be considered as one of the most commercialized cities in Sri Lanka where highly frequent trips could be observed. Some of the most used main roads for travelling would be High-Level Road, LowLevel Road, Galle Road and Baseline Road. Accordingly, four schools were selected which consisted of six school gates facing the HighLevel Road and Galle Road. Table 1 shows the selected schools for this study along with a gate notation for each school. It has to be mentioned that Royal College, Colombo 07 and St. Peter's College, Colombo 04 consisted of two school gates while other schools consisted of one each.

\subsection{Data Collection}

The data collection was conducted under three types of classifications which are mentioned as follows:

(i) Road inventory data collection near the selected schools

(ii) Crash data collection/filtering Data filtering from the Sri Lanka crash database is a required step to screen out the children related crashes at the selected locations.

(iii) Data collection on pedestrian road risk behaviour

Table 1 - School Gates Notation

\begin{tabular}{|l|c|}
\hline \multicolumn{1}{|c|}{ School Name } & $\begin{array}{c}\text { School Gate } \\
\text { Notation }\end{array}$ \\
\hline Royal College, Colombo 07 & 1,2 \\
\hline St. Peter's College, Colombo 04 & 3,4 \\
\hline Visakha Vidyalaya, Colombo 05 & 5 \\
\hline Anula Vidyalaya, Nugegoda & 6 \\
\hline
\end{tabular}

Subsequently, after the data collection process, analysis was carried out to determine the pedestrian behaviour risk values.

\subsubsection{Road Inventory Data Collection \& Analysis}

The road inventory data collection was based on the road geographical conditions in a manner to identify the features of roads near selected school areas. During this data collection, road features and parameters such as lane width, number of lanes, availability of refuges, distance to pedestrian crossings, availability of sidewalks, sidewalk width, availability of guard rails, elevation of sidewalks were studied. The obtained data are shown in Tables $2 \& 3$.

\subsubsection{Crash Data Collection \& Analysis}

Next, crash data was collected which was required for estimating the EPDO values in order to calculate pedestrian behaviour risk values. The crash data records for the year 2017 in Sri Lanka were obtained from Sri Lanka Traffic Police through University of Moratuwa. During this analysis, the records were filtered considering the city, roads and as well approximately considering a road length of $50 \mathrm{~m}$ from each side of the school gate of the selected schools. 
Table 2 - Road Inventory Data Collection

Related to Sidewalks

\begin{tabular}{|c|c|c|c|c|}
\hline Gate & 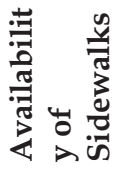 & 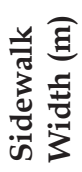 & 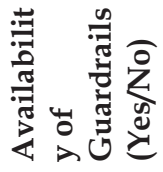 & 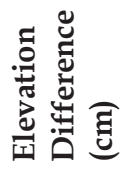 \\
\hline 1 & Yes & 2.9 & No & 15 \\
\hline 2 & Yes & 2.9 & No & 15 \\
\hline 3 & Yes & 3.2 & No & 15 \\
\hline 4 & Yes & 1.5 & Yes & 15 \\
\hline 5 & Yes & 1.8 & Yes & 5 \\
\hline 6 & Yes & 1.3 & No & 0 \\
\hline
\end{tabular}

Table 3 - Road Inventory Data Collection Related to Crosswalks

\begin{tabular}{|c|c|c|c|c|}
\hline Gate & 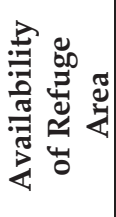 & 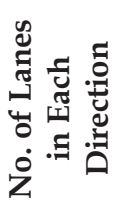 & 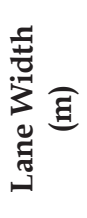 & 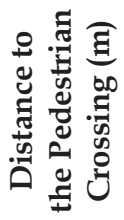 \\
\hline 1 & No & $\begin{array}{c}3 \\
\text { (one- } \\
\text { way) }\end{array}$ & 3.3 & 43.6 \\
\hline 2 & No & $\begin{array}{c}3 \\
\text { (one- } \\
\text { way) }\end{array}$ & 3.3 & 19.2 \\
\hline 3 & No & $\begin{array}{c}4 \\
\text { (one- } \\
\text { way) }\end{array}$ & 3 & 7.6 \\
\hline 4 & No & $\begin{array}{c}3 \\
\text { (one- } \\
\text { way) }\end{array}$ & 2.9 & 34 \\
\hline 5 & No & 1 & 2.6 & 4.1 \\
\hline 6 & Yes & 2 & 3.5 & 4.3 \\
\hline
\end{tabular}

Four crash severities recorded in the report card are: Fatal, Grievous, Non-grievous, and Damage Only. As observed, property damage only crashes are underreported in Sri Lanka. However, comparison among multiple sites on road safety cannot be done without converting the crash frequencies to Equivalent Property Damage Only (EPDO) crashes.

The weightages for different crash severities for EPDO calculations were computed based on the economic cost estimated for fatal, grievous, and non-grievous accidents in Sri Lanka using a guideline prepared by the Department of National Planning, Sri Lanka and some other local literature. However, the full version of the equation can be directly taken from Pasindu et al. (2021). According to Pasindu et.al (2021), EPDO can be estimated by Equation 2:
$\mathrm{EPDO}=14.6 \mathrm{~F}+8 \mathrm{G}+1.4 \mathrm{~N}+1 \mathrm{D}$

where,

EPDO =Equivalent Property Damages Only

crashes,

$\mathrm{F}=$ number of fatal crashes,

$\mathrm{G}=$ number of grievous crashes,

$\mathrm{N}=$ number of non-grievous crashes, and

$\mathrm{D}=$ number of damages only crashes.

Table 4 provides crash data statistics near the selected schools for year 2017. Thereafter, using the crash data, EPDO values were estimated near each school zone using Equation 2.

Table 4 - Pedestrian Crash Data Near the Selected Schools (2017)

\begin{tabular}{|c|c|c|c|c|}
\hline Category & 胥 & 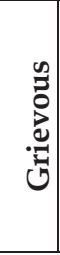 & $\begin{array}{l}0 \\
0 \\
0 \\
0 \\
0 \\
0 \\
\vdots \\
\vdots \\
0 \\
Z\end{array}$ & 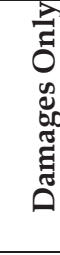 \\
\hline \multicolumn{5}{|c|}{ Royal College, Colombo 07} \\
\hline $\begin{array}{l}\text { Not using Pedestrian } \\
\text { Crossings }\end{array}$ & 0 & 1 & 1 & 1 \\
\hline Not using Sidewalks & 0 & 0 & 1 & 1 \\
\hline \multicolumn{5}{|c|}{ St Peter's College, Colombo 04} \\
\hline $\begin{array}{l}\text { Not using Pedestrian } \\
\text { Crossings }\end{array}$ & 0 & 0 & 1 & 2 \\
\hline Not using Sidewalks & 0 & 0 & 1 & 1 \\
\hline \multicolumn{5}{|c|}{ Visakha Vidyalaya, Colombo 05} \\
\hline $\begin{array}{l}\text { Not using Pedestrian } \\
\text { Crossings }\end{array}$ & 0 & 1 & 2 & 2 \\
\hline Not using Sidewalks & 0 & 0 & 5 & 3 \\
\hline \multicolumn{5}{|c|}{ Anula Vidyalaya, Nugegoda } \\
\hline $\begin{array}{l}\text { Not using Pedestrian } \\
\text { Crossings }\end{array}$ & 0 & 1 & 0 & 2 \\
\hline Not using Sidewalks & 0 & 0 & 0 & 2 \\
\hline
\end{tabular}

The data collection done at the specific zones near the selected schools and a $100 \mathrm{~m}$ length of road section was taken into consideration. Taking the centre as the school gate, $50 \mathrm{~m}$ downstream and $50 \mathrm{~m}$ upstream were considered. As mentioned in Table 1, two road sections were considered at some schools as they have two school gates in use.

Thereafter, the data collection process was carried out at certain time periods in July 2019. It was conducted in two sessions per day which covered the school starting and ending stretches.

The two sessions used for the analysis were:

1) 06.45 a.m. - 08.00 a.m.

2) 01.00 p.m. -02.00 p.m. 
All these time durations were divided into 15minute intervals considering detailed analysis. In addition to the above two time slots, 11.00am to 12.00 noon was also observed. However, due to low number of pedestrians during that session as shown in Table 5, it caused erroneous results in data analysis. Hence, that session was eliminated from further analysis.

In fact, the data collection based on the pedestrian behaviour was a key factor during the analysis since it was directly related to determining pedestrian behaviour risk values. Two aspects on pedestrian road risk behaviour were considered during the data collection which are stated as:

1) The use of pedestrian crossings by school children.

2) The use of sidewalks by school children.

Two groups conducted the data collection within the $100 \mathrm{~m}$ scope for a particular day. One group counted the number of students who were using and not using the pedestrian crossings and the other group on the same day counted the number of students who were using and not using the sidewalks. Figures 2, 3, $4 \& 5$ are some captures from the data collection points to illustrate the physical appearance of these points.

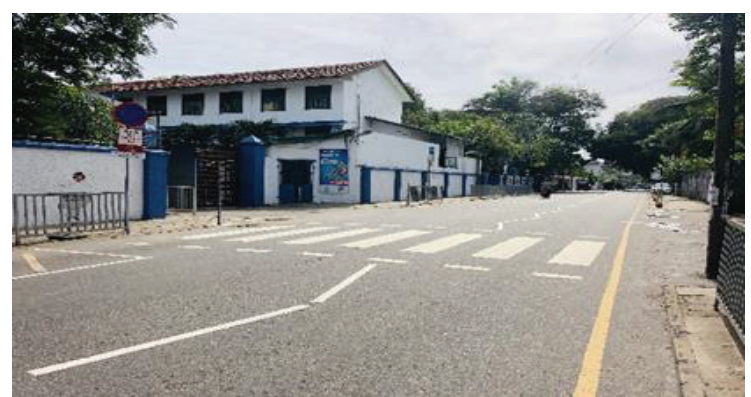

Figure 1 - Location of the Data Collection at Visakha Vidyalaya, Colombo 5

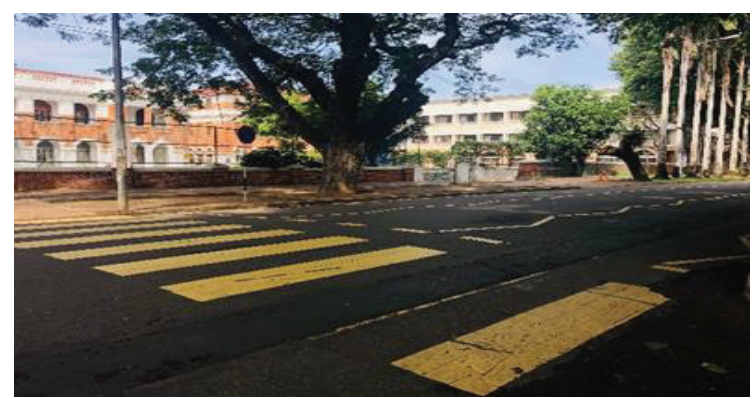

Figure 2 - Location of the Data Collection at Royal College, Colombo 7

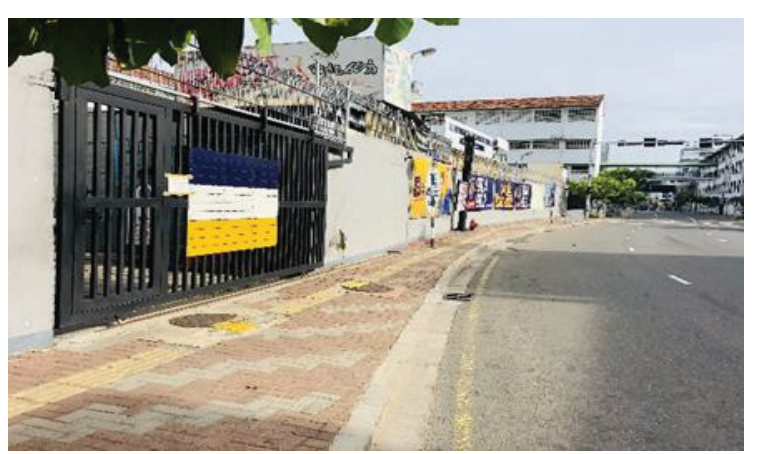

Figure 3 - Location of the Data Collection at St. Peter's College, RA De Mel Road

All the counts were done manually using tally counters and the counting process was repeated for three days for each school and altogether 12 days were spent on the four selected schools. It has to be mentioned that the counting was conducted for three days for each school in order to increase the accuracy of the data.

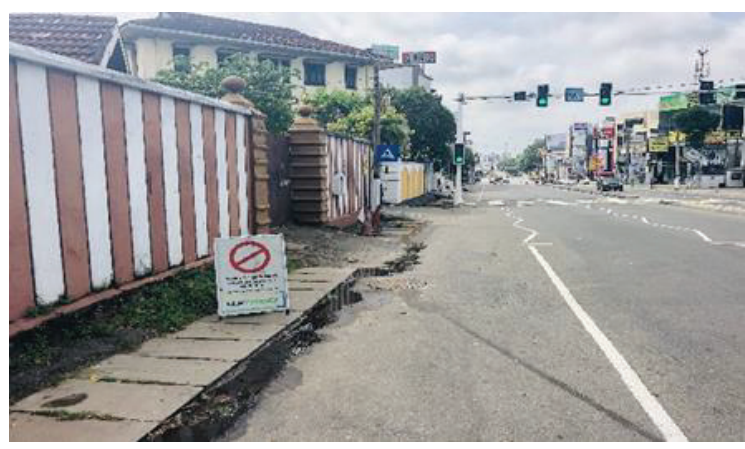

Figure 4 - Location of Data Collection at Anula Vidyalaya, Nugegoda

Table 5 indicates the data collection based on pedestrian usage of sidewalks near Royal College. Similarly, the data collection was carried out at other schools as well.

Following values were calculated to determine the pedestrian behaviour risk values near each school zone.

1) Vulnerability values for pedestrians not using pedestrian crossings and not using sidewalks.

2) Normalized vulnerability values for pedestrians not using pedestrian crossings and sidewalks.

The following equations were derived as modified versions from equations found in literature [13]. Vulnerability values for not using pedestrian crossings were calculated using Equation 3.

$V_{x 1}=\frac{N x 1}{A} \times 100 \%$ 
where, $V_{x 1}=$ vulnerability for not using pedestrian crossing behaviour, $N_{x 1}=$ number of pedestrians who did not use pedestrian crossings and $A=$ total number of pedestrians who crossed the road.

To calculate vulnerability for not using sidewalks, Equation 4 was used.

$V_{x 2}=\frac{N x 2}{A} \times 100 \%$

where,

$V x_{2}=$ vulnerability for not using sidewalks behaviour,

$N_{x 2}=$ number of pedestrians not using sidewalks and

$A=$ total number of pedestrians walked on the road.

Table 5 - Pedestrian Behavior Risk Data Collection Near Royal College

Royal College - Gate 01

\begin{tabular}{|l|c|c|}
\hline \multicolumn{1}{|c|}{ Time } & $\begin{array}{c}\text { Using } \\
\text { Sidewalks }\end{array}$ & $\begin{array}{c}\text { Not Using } \\
\text { Sidewalks }\end{array}$ \\
\hline $06.45-07.00 \mathrm{am}$ & 430 & 64 \\
\hline $07.00-07.15 \mathrm{am}$ & 937 & 112 \\
\hline $07.15-07.30 \mathrm{am}$ & 1,007 & 213 \\
\hline $07.30-07.45 \mathrm{am}$ & 103 & 26 \\
\hline $07.45-08.00 \mathrm{am}$ & 37 & 11 \\
\hline \multicolumn{2}{|c|}{} & 2 \\
\hline $11.00-11.15 \mathrm{am}$ & 5 & 0 \\
\hline $11.15-11.30 \mathrm{am}$ & 6 & 9 \\
\hline $11.30-11.45 \mathrm{am}$ & 33 & 4 \\
\hline $11.45 \mathrm{am}-12.00 \mathrm{pm}$ & 114 & 22 \\
\hline \multicolumn{2}{|c|}{} \\
\hline $01.00-01.15 \mathrm{pm}$ & 1,121 & 186 \\
\hline $01.15-01.30 \mathrm{pm}$ & 758 & 99 \\
\hline $01.30-01.45 \mathrm{pm}$ & 128 & 22 \\
\hline $01.45-02.00 \mathrm{pm}$ & \multicolumn{2}{|c|}{} \\
\hline
\end{tabular}

The vulnerability factors near school zones were then calculated using Equations 3 \& 4 for each day and correspondingly the variation of vulnerability values for all three days of data collection for each school were analysed using graphical illustration methods. Moreover, values for the normalized vulnerability were calculated for not using pedestrian crossings and not using sidewalks using Equations 5 and 6 , respectively [13].
$N V x 1=\frac{V x 1}{[\text { [Vx of All Scool Zones }]}$

where, $N x_{1}=$ normalized vulnerability value for not using pedestrian crossings.

$N V x 2=\frac{V x 2}{[\text { [VxofAllScoolZones }]}$

where, $N x_{2}=$ normalized vulnerability value for not using sidewalks.

The definition is not the same as what is used by the reference literature [13].

\subsection{Calculation of Pedestrian Behaviour Risk Values Near School Zones}

Afterwards, using the EPDO values and normalized vulnerability values for each of the school zone from above calculations, the pedestrian behaviour risk values were calculated near each school zone using Equation 7. Crash rate itself is not a true indicator on road safety. Modern road reports around the world have identified road users feeling unsafe, any potential to meet with a crash, conflict, road rule violations etc. should be considered as surrogate measures to determine the road risk. Due to underreporting and many other factors, crashes no longer directly announce road safety risk [15]. Hence, this estimation or the prediction can present a normalized risk because any such violation observed has the potential to result in a crash of some severity (See Equation 7).

Pedestrian Behaviour Risk

$=\sum\left(N V_{x} \times E P D O\right.$ of one school Zone $)$

\section{Results and Discussion}

Results for this study were based on graphical representation method. Tables 6 to 10 and graphs from Figures 6 to 9, present the results obtained from previous calculations as stated in the methodology.

\subsection{Results on Vulnerability Percentages Near Selected School Zones}

The illustration and data on vulnerability as a percentage at the selected locations in the morning period are shown in Table 6 and for the afternoon in Table 7. Values in Tables 6 and 7 are obtained by averaging over the number of days observed. Further, they are averaged for a 15-minute interval within $06.45 \mathrm{am}$ and $8.00 \mathrm{am}$ and $01.00 \mathrm{pm}$ to $02.00 \mathrm{pm}$. The illustration and data on vulnerability as a percentage at the selected location in the 
afternoon period are shown from Figures 5 to 8. Because both gates of the Royal College have similar inventory data for the sidewalks, they are averaged together. However, St. Peter's College has different sidewalk widths at the two gates, hence illustrated separately.

The vulnerability value behaves almost similarly at all schools, and it gradually increases within the early morning session.

Outliers are observed at Royal College at $01.30 \mathrm{pm}$ onwards due to a variation in the student groups that exited the school. Other than that, behaviour is almost similar for the vulnerability value at all schools, and it is gradually reduced within the hour.

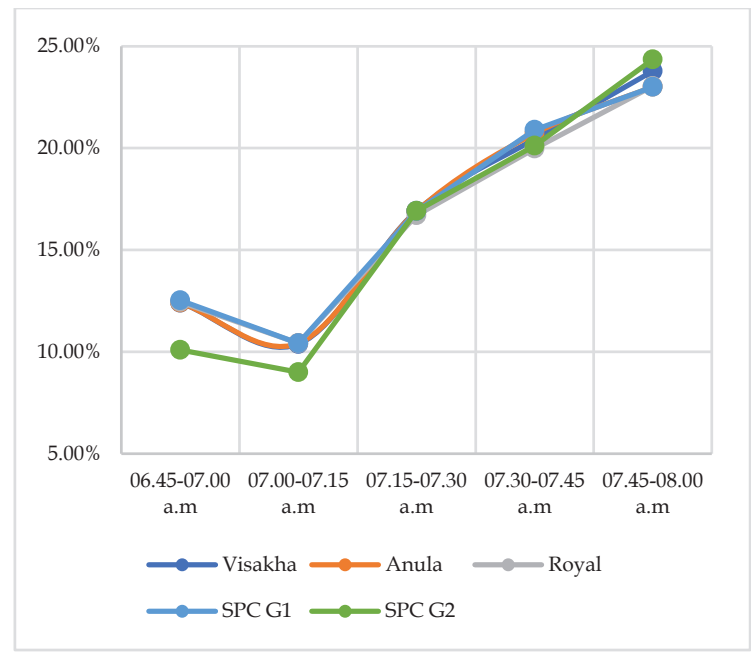

Figure 5 - Not Using Pedestrian Sidewalks vs. Time (Early Morning)

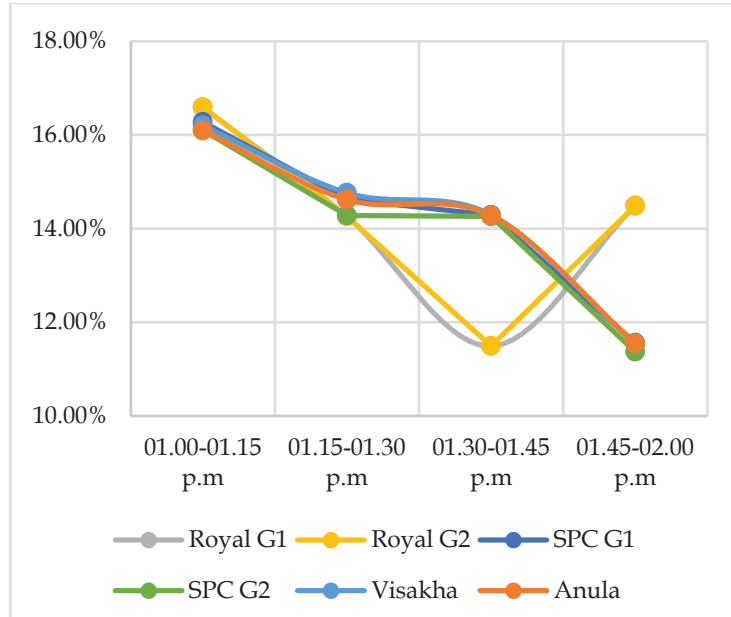

Figure 6 - Not Using Pedestrian Sidewalks vs. Time (Afternoon)

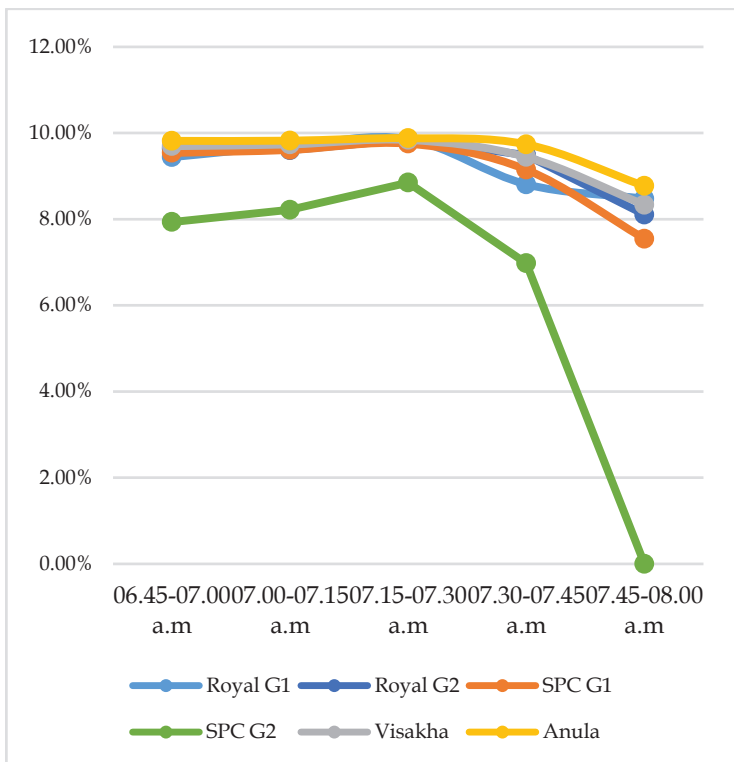

Figure 7 - Not Using Pedestrian Crossings vs. Time (Early Morning)

The total number of students who crossed the road were over 1,000 for all gates, other than Gate 2 of St. Peter's College. There were only 305 students crossing the road at the Gate 2 of St. Peter's College and it was only 13 students during $07.45 \mathrm{am}$ to $08.00 \mathrm{am}$. These small numbers show a different graph in Figure 7. Two gates for the same school were not averaged as crossing conditions were not the same for all gates. A similar situation was observed in the afternoon session as well.

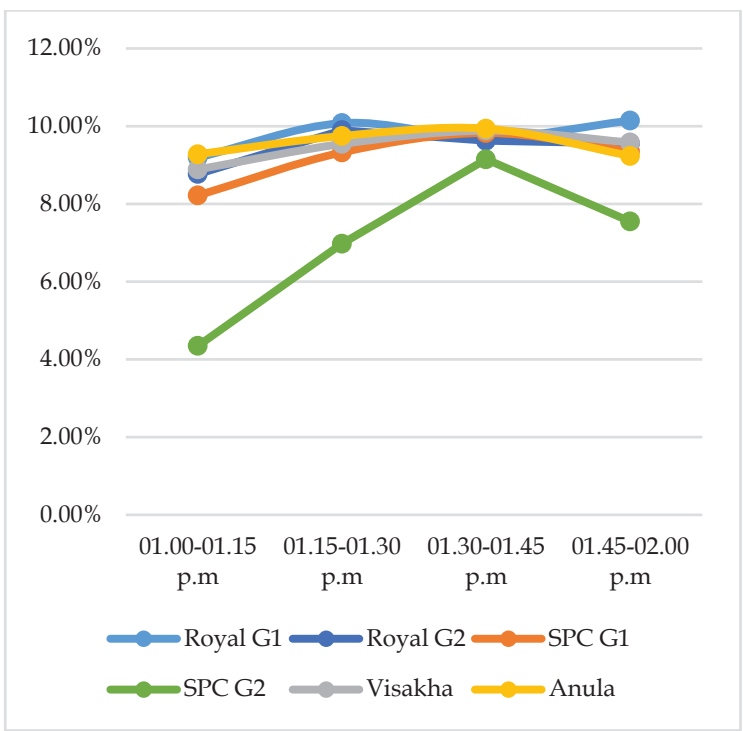

Figure 8 - Not Using Pedestrian Crossings vs. Time (Afternoon)

The results showed that the vulnerability values for each school zone were not varying much, and they almost showed similar values. 

Values Near Selected School Zones

Results obtained from Equations 5 and 6 for the normalized vulnerability values for the selected school zones are illustrated in Tables 6 \& 7. Table 6 is for the early morning session from 6.45 am and Table 7 is for the afternoon session from $01.00 \mathrm{pm}$. It can be observed that the normalized vulnerability values do not vary much over the different school zones.

Table 6 -Vulnerability Percentages (Morning $06.45-08.00$ )

\begin{tabular}{|l|c|c|}
\hline \multirow{2}{*}{ School Zone } & \multicolumn{2}{|c|}{ Vulnerability } \\
\cline { 2 - 3 } & $\begin{array}{l}\text { Not using } \\
\text { pedestrian } \\
\text { crossings }\end{array}$ & $\begin{array}{l}\text { Not using } \\
\text { sidewalks }\end{array}$ \\
\hline $\begin{array}{l}\text { Royal College, } \\
\text { Gate 01 }\end{array}$ & $9.26 \%$ & $16.39 \%$ \\
\hline $\begin{array}{l}\text { Royal College, } \\
\text { Gate 02 }\end{array}$ & $9.34 \%$ & $16.64 \%$ \\
\hline $\begin{array}{l}\text { St. Peter's } \\
\text { College, Gate 01 }\end{array}$ & $9.12 \%$ & $16.75 \%$ \\
\hline $\begin{array}{l}\text { St. Peter's } \\
\text { College, Gate 02 }\end{array}$ & $6.40 \%$ & $16.10 \%$ \\
\hline $\begin{array}{l}\text { Visakha } \\
\text { Vidyalaya }\end{array}$ & $9.41 \%$ & $16.79 \%$ \\
\hline Anula Vidyalaya & $9.61 \%$ & $16.69 \%$ \\
\hline
\end{tabular}

Table 7 -Vulnerability Percentages (Afternoon $01.00-02.00$ )

\begin{tabular}{|l|c|c|}
\hline \multirow{2}{*}{ School Zone } & \multicolumn{2}{|c|}{ Vulnerability } \\
\cline { 2 - 3 } & $\begin{array}{l}\text { Not using } \\
\text { pedestrian } \\
\text { crossings }\end{array}$ & $\begin{array}{l}\text { Not using } \\
\text { sidewalks }\end{array}$ \\
\hline $\begin{array}{l}\text { Royal College, } \\
\text { Gate 01 }\end{array}$ & $9.78 \%$ & $14.18 \%$ \\
\hline $\begin{array}{l}\text { Royal College, } \\
\text { Gate 02 }\end{array}$ & $9.46 \%$ & $14.21 \%$ \\
\hline $\begin{array}{l}\text { St. Peter's } \\
\text { College, Gate 01 }\end{array}$ & $9.18 \%$ & $14.19 \%$ \\
\hline $\begin{array}{l}\text { St. Peter's } \\
\text { College, Gate 02 }\end{array}$ & $7.01 \%$ & $14.00 \%$ \\
\hline $\begin{array}{l}\text { Visakha } \\
\text { Vidyalaya }\end{array}$ & $9.48 \%$ & $14.20 \%$ \\
\hline Anula Vidyalaya & $9.55 \%$ & $14.13 \%$ \\
\hline
\end{tabular}

\subsection{Results on EPDO (Equal Property Damage Only) Values}

Results for the EPDO values were obtained considering road rule violations of not using pedestrian crossings and not using sidewalks for the selected school zones as stated in Table 10.
Table 8 - Normalized Vulnerability Values (Morning 06.45 - 08.00)

\begin{tabular}{|l|c|c|}
\hline \multirow{2}{*}{ School Zone } & \multicolumn{2}{|c|}{ Normalized Vulnerability } \\
\cline { 2 - 3 } & $\begin{array}{l}\text { Not using } \\
\text { pedestrian } \\
\text { crossings }\end{array}$ & $\begin{array}{l}\text { Not using } \\
\text { sidewalks }\end{array}$ \\
\hline $\begin{array}{l}\text { Royal College, } \\
\text { Gate 01 }\end{array}$ & 0.174 & 0.165 \\
\hline $\begin{array}{l}\text { Royal College, } \\
\text { Gate 02 }\end{array}$ & 0.176 & 0.167 \\
\hline $\begin{array}{l}\text { St. Peter's College, } \\
\text { Gate 01 }\end{array}$ & 0.172 & 0.169 \\
\hline $\begin{array}{l}\text { St. Peter's College, } \\
\text { Gate 02 }\end{array}$ & 0.120 & 0.162 \\
\hline Visakha Vidyalaya & 0.177 & 0.169 \\
\hline Anula Vidyalaya & 0.181 & 0.168 \\
\hline
\end{tabular}

Table 9 - Normalized Vulnerability Values (Afternoon 01.00 - 02.00)

\begin{tabular}{|l|c|c|}
\hline \multirow{2}{*}{ School Zone } & \multicolumn{2}{|c|}{ Normalized Vulnerability } \\
\cline { 2 - 3 } & $\begin{array}{l}\text { Not using } \\
\text { pedestrian } \\
\text { crossings }\end{array}$ & $\begin{array}{l}\text { Not using } \\
\text { sidewalks }\end{array}$ \\
\hline $\begin{array}{l}\text { Royal College, } \\
\text { Gate 01 }\end{array}$ & 0.184 & 0.143 \\
\hline $\begin{array}{l}\text { Royal College, } \\
\text { Gate 02 }\end{array}$ & 0.178 & 0.143 \\
\hline $\begin{array}{l}\text { St. Peter's College, } \\
\text { Gate 01 }\end{array}$ & 0.173 & 0.143 \\
\hline $\begin{array}{l}\text { St. Peter's College, } \\
\text { Gate 02 }\end{array}$ & 0.132 & 0.141 \\
\hline $\begin{array}{l}\text { Visakha } \\
\text { Vidyalaya }\end{array}$ & 0.178 & 0.143 \\
\hline Anula Vidyalaya & 0.180 & 0.142 \\
\hline
\end{tabular}

Table 10 - Results of the EPDO Crash Values

\begin{tabular}{|l|r|r|}
\hline \multirow{2}{*}{ School Zone } & \multicolumn{2}{|c|}{ EPDO Crashes } \\
\cline { 2 - 3 } & $\begin{array}{l}\text { Not using } \\
\text { pedestrian } \\
\text { crossings }\end{array}$ & $\begin{array}{l}\text { Not using } \\
\text { sidewalks }\end{array}$ \\
\hline Royal College & 10.4 & 2.40 \\
\hline St. Peter's College & 3.40 & 2.40 \\
\hline Visakha Vidyalaya & 12.80 & 10.00 \\
\hline Anula Vidyalaya & 10.00 & 2.00 \\
\hline
\end{tabular}

According to Table 10, school zone of the Visakha Vidyalaya, Colombo 5 has the highest EPDO, which makes it the most crash prone location among the selected school zones. That is observed in both crossing crashes as well crashes related to walking by the roadside. 
However, a significant increase of risk taking was not observed there compared to the other schools. Hence, the high crash severities may be because of road related factors or with the traffic flow characteristics.

\subsection{Results on Pedestrian Behavior Risk Values}

Afterwards, pedestrian behaviour risk values near selected school zones were compared with the road inventory data.

According to Figure 9, the distance to crosswalks has not shown an effect on the vulnerability of not using the crosswalks. At St. Peter's College - Gate 02, there is a pedestrian guard rail, and the crosswalk is provided about $34 \mathrm{~m}$ away from the gate. This might have been the reason for lowest violation rates at this place. Even though a pedestrian guard rail is provided at Visakha Vidyalaya too, the crosswalk is only about $4 \mathrm{~m}$ from the gate and the students have considered crossing close to the painted crosswalk is ok. Hence, the violation rates are comparatively high at Visakha Vidyalaya.

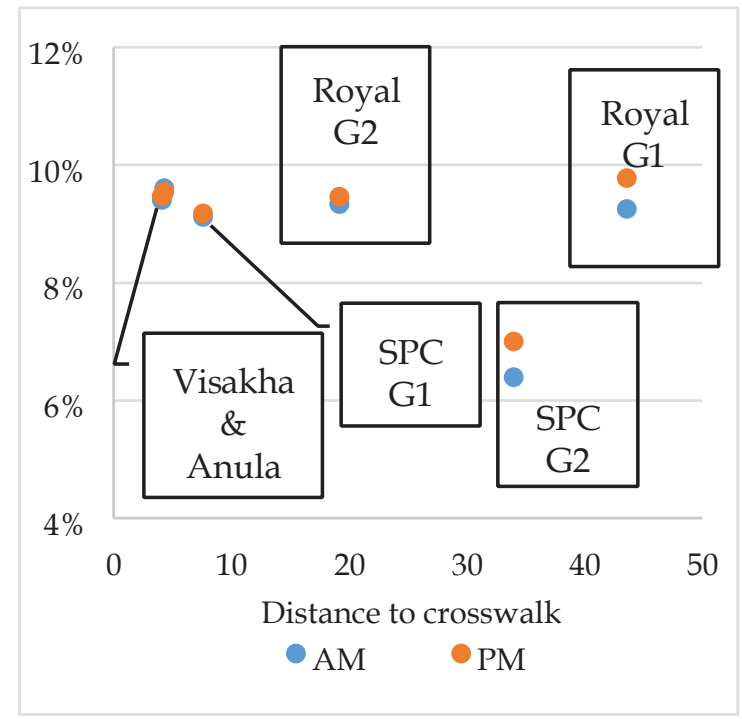

$\mathrm{SPC}=$ St Peter's College

Figure 9 - Crossing Vulnerability vs. Distance to Crosswalk

No relationship was observed between width across the road to cross, or the number of lanes to cross, or the presence of a refuge and crossing vulnerability either. Furthermore, the correlation check using graphical illustrations showed that there is no significant relationship could be recognized between the sidewalk width or the elevation difference and 'vulnerability of not using sidewalks'.
One past study showed that, while an underpass was provided with a median railing barrier at-grade, 22\% of pedestrians (all ages) still crossed the road at-grade [16]. It was observed that the provided median railings have had some openings from where people crossed, and some pedestrians were observed jumping over the barrier. In another study done in Pakistan, it was stated that pedestrians used non-designated areas to cross the street and, out of 100 pedestrians who had a zebra crossing available to them, only 23 used it to cross the street [17].

Accordingly, the calculated pedestrian behaviour risk values are not significantly high values. This showed that the considered school zones were safe for pedestrians. Further, the requirements for improvement regarding pedestrian safety should not necessarily be a high priority considering the current conditions.

\section{Conclusions}

Typically, school zones are highly crowded with pedestrians, and comprise school children walking in groups or individually with or without having necessary awareness on road rules. Increasing traffic congestion could be identified near school zones during school starting and ending times where every road user has responsibility for this situation. The behaviour of school children as pedestrians with or without an adult accompanying them, plays an important role in the pedestrian safety.

This study focussed on analysing pedestrian safety based on behaviour risk near school zones in Colombo and the results showed that the vulnerability values for not using pedestrian crossings and not using sidewalks over time with each selected school zone had almost similar values. Normalized risk values were also similar to all the selected school zones. These risk values from the current study were less than the reported risk values found in literature and therefore, the pedestrian safety near the selected schools in the Colombo area could be considered as safe for the current traffic conditions.

Further, in the selected data samples, there were no significant relationships between the road inventory data and pedestrian risk behaviour. This supports many literature that recommend school children awareness is the 
best way to improve children behavior as pedestrians.

\section{References}

1. World Health Organization, "Global Status Report on Road Safety 2018: Summary," 2018. [Online]. Available: http://apps.who.int/bookorders.

2. Ivan, J. N. and Ravishanker, N., "Pedestrian Safety Analysis," Wiley StatsRef: Statistics Reference Online, John Wiley \& Sons, Ltd., 2019, pp. 1-6. doi: 10.1002/9781118445112.stat08217.

3. Hazzard, K. and Hildebrand, B.S.E., "School Zone Safety: Are We Pandering to Parents?," 2015 Conference of the Transportation Association of Canada, 2015, pp. 1-16. Available: https://www.tacatc.ca/en/conference/papers/school-zone-safetyare-we-pandering-parents.

4. Macpherson, A., Roberts, I., and Pless, I.B., "Children's Exposure to Traffic and Pedestrian Injuries," American Journal of Public Health, Vol. 88, No. 12, pp. 1840-1843, 1998, doi: 10.2105/ AJPH.88.12.1840.

5. Warsh, J., Rothman, L., Slater, M., Steverango, C., and Howard, A., "Are School Zones Effective? An Examination of Motor Vehicle Versus Child Pedestrian Crashes Near Schools," Injury Prevention, Vol. 15, No. 4, pp. 226-229, Aug. 2009, doi: 10.1136/ip.2008.020446.

6. Barton, B. K. and Schwebel, D. C., "The Roles of Age, Gender, Inhibitory Control, and Parental Supervision in Children's Pedestrian Safety," Journal of Pediatric Psychology, Vol. 32, No. 5, pp. 517-526, Apr. 2007, doi: 10.1093/jpepsy/jsm014.

7. Hamed, M. M., "Analysis of Pedestrians' Behavior at Pedestrian Crossings," Safety Science, Vol. 38, No. 1, pp. 63-82, Jun. 2001, doi: 10.1016/S09257535(00)00058-8.

8. Leden, L., Gårder, P., and Johansson, C., "Safe Pedestrian Crossings for Children and Elderly," Accident Analysis and Prevention, Vol. 38, No. 2, pp. 289-294, Mar. 2006, doi: 10.1016/j.aap.2005.09.012.

9. Andreou, M., "Planning for Pedestrian Safety Around Schools," Sydney, 2009.

10. Transportation Services Toronto, "Staff Report for Action on School Zone Safety Strategy", Toronto, 2014. Accessed: Feb. 25, 2021. [Online]. Available: http://www.toronto.ca/legdocs/mmis/2013/mm /bgrd/backgroundfile-65172.pdf.

11. Sharmeen, J., Abontika, and Israt, S., "Mobility and Accessibility Problems around Schools in Dhaka (Bangladesh): A Case Study," International Journal of Civil Engineering (IJCE), Vol. 2, No. 2, pp. 1-8, May 2013.
12. Kourtellis, A., Lin, P. S., and Gawade, M., "Measuring Unsafe Pedestrian Behavior Using Observational Data" TRB 2013 Annual Meeting Paper revised from original submittal," in TRB 2013 - 92nd Annual Meeting, Jan. 2013, pp. 1-17.

13. Wicramasinghe, V. and Dissanayake, S., "Evaluation of Pedestrians' Sidewalk Behavior in Developing Countries," in Transportation Research Procedia, Jan. 2017, Vol. 25, pp. 4068-4078. doi: 10.1016/j.trpro.2017.05.327.

14. Pasindu, H. R., Ranawaka, R. K. T. K., Sandamal, R. M. K., Thanuwara, H.V., and Dias, T. W. K. I. M., "Incorporating Road Safety in Rural Road Network Level Pavement Management," Jan. 2021. Accessed: Jun. 27, 2021. [Online]. Available: DOI: 10.13140/RG.2.2.27216.43524.

15. Cafiso, S., García, A. G., Cavarra, R., and Rojas, M. A. R., "Crosswalk Safety Evaluation Using a Pedestrian Risk Index as Traffic Conflict Measure," Sep. 2011, Accessed: Jun. 28, 2021. [Online]. Available:

http://onlinepubs.trb.org/onlinepubs/conferences /2011/RSS/2/Cafiso,S.pdf.

16. Gupta, U., G. Tiwari, N. Chatterjee, and Fazio, J., "Case Study of Pedestrian Risk Behavior and Survival Analysis," Proceedings of the Eastern Asia Society for Transportation Studies, Vol. 7, pp. 389-389, 2009, doi: 10.11175/EASTPRO.2009.0.389.0.

17. Khan, F. M., Jawaid, M., Chotani, H., and Luby, S., "Pedestrian Environment and Behavior in Karachi, Pakistan," Accident Analysis and Prevention, Vol. 31, No. 4, pp. 335-339, Jul. 1999, doi: 10.1016/S00014575(98)00075-X. 